\title{
Utilization Starch of Avocado Seed (Persea Americana Mill.) as a Raw Material for Dextrin
}

\author{
Maryam $^{1}$, Anwar Kasim² and Santosa ${ }^{2}$ \\ 1. Agro-Industrial Engineering Department, Polytechnic of ATI Padang, Jl. BungoPasang, Tabing 25171, Padang, West Sumatra \\ 2. Faculty of Agricultural Technology, Andalas University, Jl. LimauManis, Pauh 25163, Padang, West Sumatra
}

\begin{abstract}
Starch ofavocado seeds can be used as an alternative source of starch because it contains $80.1 \%$ starch. Natural starch can be made into a modified starch, for example dextrin. Dextrin can be made by using acid or enzyme hydrolysis. The purposes of this research were determine the concentration of hydrochloric acid $(\mathrm{HCl})$, the temperature and heating timein the optimum process of hydrolysis of starch into dextrin and to determine the quality of the resulting product dextrin terms of Indonesian National Standard 01-2593-1992. The methode was used in this research is hydrolisis with hydrochloric acid ( $\mathrm{HCl})$. The results processing into starch avocado seed yield is $23.15 \%$. $\mathrm{HCl}$ concentration, temperature and heating time significantly affect the value of dextrose equivalent (DE), viscosity and part soluble in cold water. There is interaction between $\mathrm{HCl}$ concentration, temperature and heating time on the value of DE, viscosity and part soluble in cold water. Optimum conditions of process was obtained at a concentration of $0.15 \mathrm{~N} \mathrm{HCl}$, 30 minutes heating time and heating temperature of $90{ }^{\circ} \mathrm{C}$. Dextrose equivalent (DE) value is $19.61 \%$. The value of solubility in cold water is $90.19 \%$. Viscosity value is $1.61^{\circ} \mathrm{E}$. Dextrin is not accordance with the standards of quality parameters Indonesian National Standard 01-2593-1992. Dextrin produced should be applied to non-food industry.
\end{abstract}

Key words: Starch, dextrin, hydrolysis, the optimum conditions.

\section{Introduction}

Avocado (Persea americana Mill.) is one type of fruit that is potentially in Indonesia. Avocado seeds until now only be disposed of as waste that can cause environmental pollution. Avocado seeds have a water content of $12.67 \%$, ash content of $2.78 \%, 0.54 \%$ mineral content is higher than other fruit seeds. Avocado seeds are a rich source of polyphenolic compounds encompass a complex mix of simple catechin and epicatechin with the greatest polymeric substances [1]. Avocado seed contains starch which is quite high, around 23\%. Starch in avocado seed approximately $80.1 \%$. This allows the avocado seed as an alternative source of starch.

In trade there are two kinds of starch that is starch unmodified (native starch) and starches that have been modified (modified starch). Natural starches such as tapioca, corn starch, sago and other starches

Corresponding author: Maryam, S.TP, MP, research field: agricultural technology. hasseveral problems when used as raw materials in the food and nonfood industry. If the cooked starch takes a long time, also formed pasta loud and clear. Besides, it's too sticky and not resistant to acid treatment. These constraints led to the natural starch limited its use in industry [2]. Starch can naturally be made into starch modified with desired properties or in accordance with needs such as dextrin.

According to Ref. [3], dextrin is incomplete hydrolysis of starch with acid catalyst or also formed from the hydrolysis of starch using a particular enzyme. Hydrolysis of starch is a process of molecular breakdown of starch into its constituent parts are more simple as dextrin, is omaltosa, maltose and glucose [4]. The use of an acid catalyst in the hydrolysis is easier in the process, because the process is not influenced by various factors, including the condition of the substrate used or loss of activity due to temperature or $\mathrm{pH}$ ekstrim. According to Ref. [5] the factors that affect the hydrolysis is acid and starch ratio, the 
normality of the acid, temperature, time and concentration of starch suspensions.

The purpose of this study was (1) to determine hydrochloric acid $(\mathrm{HCl})$ concentration, temperature and length of time in the optimum heating of starch hydrolysis process from avocado seeds; (2) to know the quality of the resulting dextrin products based on the Indonesian National Standard 01-2593-1992.

\section{Materials and Methods}

Materials were used in this study ie the starch of avocado seed, hydrochloric acid $(\mathrm{HCl})$, natrium hidroksida $(\mathrm{NaOH})$, natrium bisulfit $\left(\mathrm{Na}_{2} \mathrm{~S}_{2} \mathrm{O}_{5}\right)$, and distilled water. The tools were used in this study include: oven, desiccator, blender, filter, stainless steel knives, analytical balance, measuring cups, goblets, magnetic stirrer, a stirrer, a thermometer, pipette, burette, erlenmeyer, flask, $\mathrm{pH}$ meter.

The methode was used in this research is hydrolisis with hydrochloric acid ( $\mathrm{HCl})$. Starch is suspended in $30 \%$ $\mathrm{HCl}$ solution of 300 grams of starch into $1,000 \mathrm{ml}$ of $\mathrm{HCl}$ concentration determined. Then heated with a magnetic stirrer is calculated from the start time to a specified temperature and stirred continuously with a speed of $450 \mathrm{rpm}$ to avoid the formation of dry gel attached to the walls and heat homogenize. After the heating time is fulfilled in accordance with the specified, starch which has hydrolysis immediately separated $\mathrm{HCl}$ solution with a vacuum pumpand then dried at $55{ }^{\circ} \mathrm{C}$ for 12 hours. After drying, the starch suspended in water and added with $0.05 \mathrm{~N} \mathrm{NaOH}$ slowly until pH 7.0 (neutral). Once the product is separated between the precipitate with distilled water by using a vacuum pump and then dried back at a temperature of $55^{\circ} \mathrm{C}$ for 12 hours, blend until smooth in order to pass 80 mesh sieve and testing.

Analysis of quality parameters include dextrin fiber content, moisture content and ash content, dextrose equivalent, the degree of acid, color (visual), the color in solution Lugol, the fraction that passes 80 mesh sieve, part of which is soluble in cold water and viscosity.
This study uses a completely randomized design (CRD) factorial with 3 factors and 3 replications. Factor (1) is the percentage concentration of $\mathrm{HCl}$. With each level is A1 $=0.05 \mathrm{~N}$; A2 $=0.1 \mathrm{~N}$; and A3 = $0.15 \mathrm{~N}$. Factor (2) is the length of heating time. With each level is B1 = 15 minutes; B2 = 30 minutes; and $\mathrm{B} 3=45$ minutes. Factor (3) is the heating temperature. With each level is $\mathrm{C} 1=70{ }^{\circ} \mathrm{C}$; $\mathrm{C} 2=80{ }^{\circ} \mathrm{C}$; and $\mathrm{C} 3=$ $90{ }^{\circ} \mathrm{C}$.

\section{Result and Discussion}

Results avocado seed processing into starch was produced yield $23.15 \%$. This allows the avocado seed as one of the alternative sources of starch. To produce starch avocado seeds of good quality, the manufacturing process, avocado seeds soaked in sodium metabisulfite at a concentration of 3,000 ppm and drying with a temperature of $50{ }^{\circ} \mathrm{C}$ [6]. Sodium metabisulfite is needed to reduce the brown color resulting in a starch white. The results analysis of starch avocado seed were used raw materials in this study are presented in Table 1.

The results analysis of dextrinwere produced in this study are presented in Table 2. This data is obtained from the best treatment in this research.

Based on the Table 2, fiber content in the dextrin was $1.81 \%$. Based on the analysis of variance was showed that the concentration of $\mathrm{HCl}$, the temperature and heating time did not significantly affect the resulting fiber in the dextrin. Fiber can not be changed in hydrolysis process. Crude fiber can be used to

Table 1 The Results analysis of starch avocado seeds.

\begin{tabular}{ll}
\hline Quality parameters & Value \\
\hline Starch levels & $85.3 \%$ \\
Color (Visual) & Brownish white \\
Ashlevels & $1.64 \%$ \\
Water content & $9.20 \%$ \\
Fiber levels & $1.86 \%$ \\
Escaped fineness 80 Mesh & $80.91 \%$ \\
Solubility in Cold Water & $40.29 \%$ \\
Viscosity & $70.19 \mathrm{cSt}$ \\
Color with Lugol solution & Blue \\
Acid degree & $0.94(0.1 \mathrm{~N} \mathrm{NaOH} / 100 \mathrm{~g})$ \\
Dextrose Equivalent (DE) & $0.00 \%$ \\
\hline
\end{tabular}


Table 2 The Results analysis of dextrin.

\begin{tabular}{ll}
\hline Quality parameters & Value \\
\hline Color (Visual) & Reddish brown \\
Ash levels & $1.62 \%$ \\
Water content & $5.16 \%$ \\
Fiber levels & $1.81 \%$ \\
Escaped fineness 80 Mesh & $91.04 \%$ \\
Solubility in Cold Water & $90.19 \%$ \\
Viscosity & $1.61{ }^{\circ} \mathrm{E}$ \\
Color with Lugol solution & purple \\
Acid degree & $1.15(0.1 \mathrm{~N} \mathrm{NaOH} / 100 \mathrm{~g})$ \\
Dextrose Equivalent (DE) & $19.61 \%$ \\
\hline
\end{tabular}

determine the purity of the material and process efficiency [7].

Water content of dextrin is $5.16 \%$. Concentration of $\mathrm{HCl}$, temperature and heating time did not significantly affect the water content of dextrin. Water content of food ingredients will determine the acceptability, freshness and durability of the food. Dextrin with low water content will be easier in storage and application.

Ash content of dextrin is $1.62 \%$. According to Ref. [8], the ash content of flour tapioca dextrin with $\mathrm{HCl}$ hydrolysis method ranged from $0.13 \%$ to $0.18 \%$.

Determination of ash content is made to determine whether there is a change after the process of forming the inorganic content of dextrin. Based on the analysis of variance showed that the concentration of $\mathrm{HCl}$, the temperature and heating time did not significantly affect the resulting ash content dextrin. Ash content will not change in the process of hydrolysis because of the heat given to the hydrolysis process is not able to reach the minerals contained in these materials.

Dextrose equivalent (DE) values of dextrin is $19.61 \%$. The percentage of reducing sugar in starch derivatives called DE. Measurement DE was performed to determine how far the hydrolyzed starch into molecules with shorter chain particularly into dextrin. Based on the analysis of variance showed that the concentration of $\mathrm{HCl}$, the temperature and heating time significantly affected DE. DE value increases with the increase of $\mathrm{HCl}$ concentration, temperature and duration of stirring as shown in Fig. 1. Commercially, the use of modified starch is affected by the $\mathrm{DE}$ value. The larger the $\mathrm{DE}$ value the greater the percentage of starch which turns into reducing sugars.

Value of solubility in cold water of dextrin is $90.19 \%$. Based on the analysis of variance showed that the concentration of $\mathrm{HCl}$, the temperature and heating time significantly affect on part soluble in cold water. From the test results obtained starch which has undergone modification process has percentage of material that is soluble in cold water higher than the starch avocado seed. This can be explained because in the process of modifying the starch to form sugars result starch polymer termination. The higher the concentration of $\mathrm{HCl}$, the temperature and heating time will result in faster hydrolysis process and the more part soluble in cold water as shown in Fig. 2. The solubility dextrin, including low due to high crude fiber content. According to Ref. [10], a large number of hydroxyl groups on dextrin lead to higher hydrophilic properties on the compound that high solubility

Viscosity values of dextrin is $1.61{ }^{\circ} \mathrm{E}$. Based on the analysis of variance showed that the concentration of $\mathrm{HCl}$, the temperature and heating time give significantly effect on the dextrin viscosity. All samples which have undergone starch hydrolysis process has a lower viscosity than native starch and having a viscosity of $9.24{ }^{\circ} \mathrm{E}$. Increasing of $\mathrm{HCl}$ concentration, temperature and duration of heating, cause decreasing the dextrin viscosity as shown in Fig. 3. At the time of termination bond hydrolysis of complex carbon compounds (polysaccharides) into monosaccharides or disaccharides. Due to the termination of the bond (degradation or depolimerasi), the viscosity decreases.

Value of acid degree of dextrin is $1.15(0.1 \mathrm{~N}$ $\mathrm{NaOH} / 100 \mathrm{~g})$. Based on the analysis of variance showed that the concentration of $\mathrm{HCl}$, the temperature and heating time did not significantly affect the degree of acid. Greatly influenced by the degree of acid neutralization technique performed after the acid hydrolysis process. 


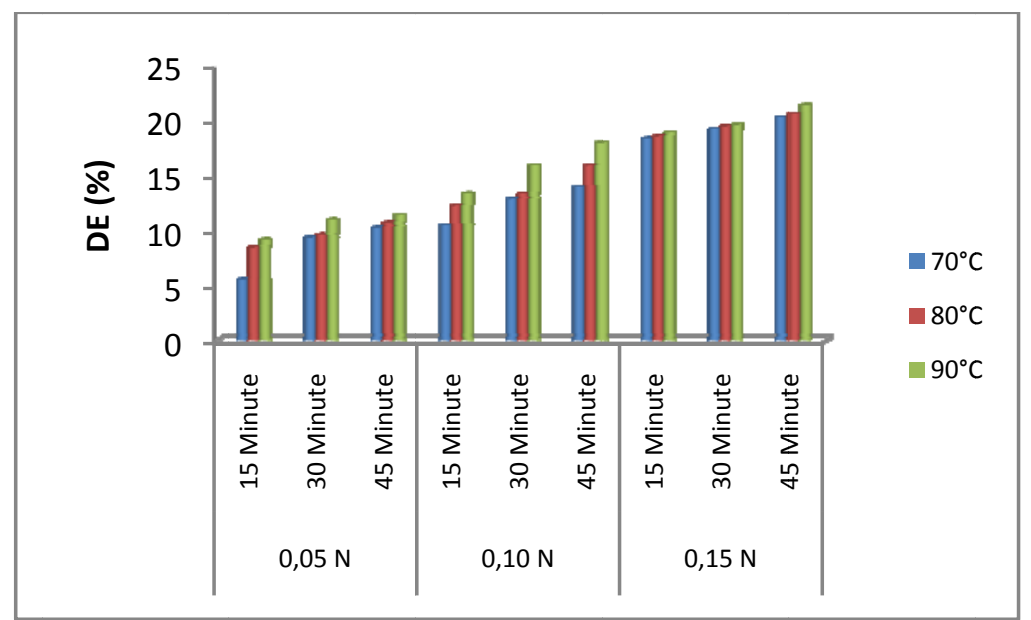

Fig. 1 Chart of DEvalue of dextrin.

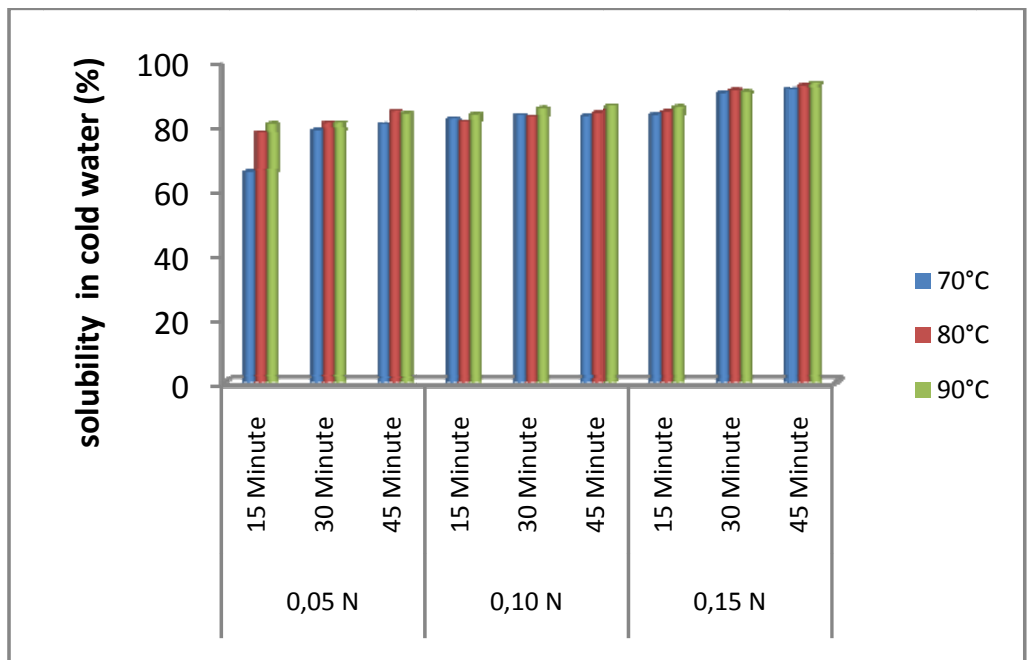

Fig. 2 Chart of part soluble in cold water of dextrin.

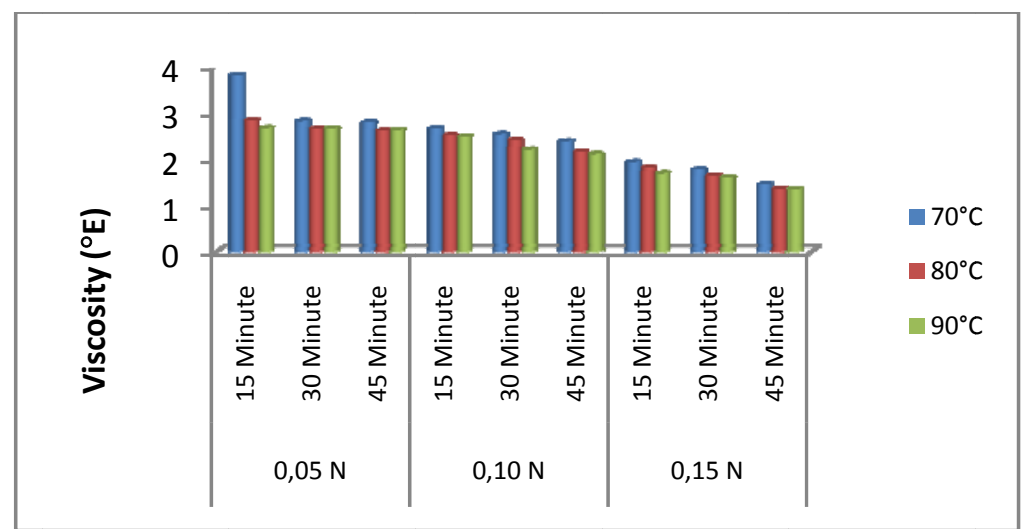

Fig. 3 Chart of dextrin viscosity.

The dextrin was dissolved in a solution of Lugol reacted is purple color. According to Ref. [11], if formed purple indicates that the dominant form of dextrin is amilodekstrin, red-brown color indicates the dominant form dextrin is eritrodekstrin.

Value of escaped fineness 80 Meshis 91.04\%. Fineness is one of the quality parameters dextrin. The more delicate an dextrin, the better quality because 
dextrin which has a high fineness will be easy in the handling of subsequent production. Based on the analysis of variance showed that the concentration of $\mathrm{HCl}$, the temperature and heating time did not significantly affect dextrin fraction that passes 80 mesh sieve.

Dextrin color produced is also determined by the National Standards, namely the Indonesian National Standard 01-2593-1992 ie white to yellowish. From the test results visually color above that samples reddish brown. Colors starch raw materials also affect the color of dextrin. The raw material used is pure white. Accordingto Ref. [11], if formed purple indicates that the dominant form of dextrin is amilodekstrin, red-brown color indicates the dominant form dextrin is eritrodekstrin.

The optimum process conditions was obtained at dextrin which has the best quality parameters and standards required to approach with Indonesian National Standard 01-2593-1992 that the treatment concentration of $0.15 \mathrm{~N} \mathrm{HCl}$, the heating time of 30 minutes and warming temperature is $90{ }^{\circ} \mathrm{C}$. Most quality parameters dextrin produced meets the standards for food applications, namely DE, viscosity, water content, escaped fineness 80 Mesh, the degree of acid and color with Lugol solution. Quality parameters solubility in cold water, crude fiber content, ash content and color is visually not meet the standards for food applications. Dextrin which will be applied to the food industry must meet all requirements of the standard quality parameters in Indonesian National Standard 01-2593-1992. The resulting dextrin should be applied to non-food industry, such as adhesive raw materials, paper industry, textiles, building materials and as a solvent mixing ingredients in insecticides and fungicides.

\section{Conclusion}

The optimum conditions in the manufacture of dextrin from avocado seed was obtained in the treatment concentration of $0.15 \mathrm{~N} \mathrm{HCl}$, the heating time of 30 minutes and the heating temperature of 90 ${ }^{\circ} \mathrm{C}$. Dextrin was produced is not accordance with Indonesian National Standard 01-2593-1992 about dextrin quality requirements for the food industry, but according to non-food industry.

\section{References}

[1] Alsuhendra, Z. R., and Lisanti, E. 2007. "Extraction and Characteristics of Phenolic Compounds from Seed Avocado (Persea americana Mill.)." In Proceedings of the National Seminar PATPI, Bandung.

[2] Pudjihastuti, I., and Sumardiono, S. 2011. "Development of Combination of Innovative Process Acid Hydrolysis Reaction and UV photochemical reactions for the Production of Modified Tapioca Starch.” In Proceedings of the National Seminar of Chemical Engineering. ISSN 1693-4393, Yogyakarta.

[3] Handodo, D. D. 2004. "Studies Water SorptionIsotermi Dextrin Starch Garut (Matantha arundinaceae L.) at Different Levels of Hydrolysis. Essay.” Faculty of Agricultural Technology. Bogor Agricultural Institute. Bogor.

[4] Rindit, P., Lanjar and Parwiyanti. 1998. Research Report: Learning the Starch Hydrolysis Bluebird (Dioscoreahispida dernst) by the Enzyme $\alpha$-amylase and AmylaseGluko for Glucose Syrup Making. Faculty of Agriculture, Sriwidjaja University, Palembang.

[5] Agra, I. B., Warnijati, S., and Pujianto, B. 1973. "Cassava Starch Hydrolysis Creep on over Temperature of $100^{\circ} \mathrm{C}$.” In Techniques Forum, University of Gadjah Mada. Vol. 3, 115-9.

[6] Masniary, L. L. 2008. Extraction of Starch from Avocado Seeds. Scientific Work. Department of Agricultural Technology. Faculty of Agriculture. North Sumatera Univercity, Medan.

[7] Sudarmadji, S., Haryono,B., and Suhardi. 1996. Procedures Analysis of Food and Agriculture. Yogyakarta: Liberty.

[8] Martadinata, A. 2010. "Preparation of Tapioca Dextrin in Hydrolysis Acid Catalysts Using HCl.” Essay. Andalas Univercity, Padang.

[9] Jati, P. W. 2006. "Effect of Timeand Concentration of HClHydrolysis to Dectrose Value Equivalent (DE) and Quality Characteristics of Tapioca Starch Modified Starch by Acid Hydrolysis Method.”Essay. Industrial Technology Department of Agriculture. Faculty of Agricultural Technology. Bogor Agricultural Institute, Bogor.

[10] Kenyon, M. 1992. Modified Starch, Maltodextrin and 
Corn Syrup Solid Material Well for Food for Encapsulation, edited by Reinccus, G. A. Ecapsulation and Controlled Released of Food Ingredient. New York: Edward Brothers Inc.
[11] Herminiati, A., and Abasa, A. 2006. "Utilization of Starch Dextrin Garut as Basic Materials Food for People with Autism.” In Proceedings of the National Seminar, Yogyakarta. 